\title{
संगीत और मानवीय आभामंडल
}

\section{सार संक्षेपिका}

समस्त जगत में जंगम व स्थावर पदार्थों के भिन्न-भिन्न प्रकार के अच्छे-बुरे गुणधर्म होते हैं, जो नज़रों मे सहज ही आ जाते हैं। यदि किसी मनुष्य में कोई विशेष गुणधर्म न हो तो उसमें मनुष्यत्त्व नहीं होगा। इसी विशेष अच्छे-बुरे गुणधर्म को ही 'आभा' कहते हैं। वैज्ञानिक भाषा में आभामंडल को ऊर्जा क्षेत्र या जैव क्षेत्र कहते हैं। संगीत मानव ही क्या समस्त जगत के प्रणियों को अपनी ओर आकर्षित करता है। संगीत से यदि मानव आकर्षित होता है तो उसके आभामंडल पर इसका प्रभाव पड़ेगा ही यह तय है। अर्थात सांगीतिक प्रभाव जिसे आज हम संगीत चिकित्सा के नाम से भी जानते हैं इसके द्वारा आभामंडल पर सकारात्मक प्रभाव डालकर बीमार लोगों को ठीक भी किया जाता है। संगीत चिकित्सा में भी मानवीय आभामंडल को वैज्ञानिक उपकरणों द्वारा देखा जाता है तथा आभामंडल की विकृत स्तिथि को देख कर उसे संगीत द्वारा ठीक किया जाता सकता है।

बीज शब्द

संगीत, आभामंडल, मानवीय आभामंडल

भूमिका

भारत की संस्कृति अपनी अवर्णनीय विशेषताओं एवं अमूल्य अनिर्वचनीय के कारण समस्त विश्व में प्रसिद्ध है। अपनी जीवन परम्पराओं एवं शाश्वत मूल्यों तथा अपरिवर्तनीय विशेषताओं के कारण सर्वत्र वन्दनीय है, सराहनीय है, अनुकरणीय है। समस्त कलाएं इसी भारतीय सभ्यता व संस्कृति की संवाहक है। कला को भारतीय संस्कृति में 'मनसत्व' कहा गया है और वह 'आत्मवत् सर्वभूतेषु' के चिन्तन से उत्प्रेरित है। कला को भारतीय संस्कृति में सत्चित्-आनन्द मे 'चित् तत्व की अभिव्यक्ति का माध्यम माना गया है। भारतीय चिन्तन के अनुसार चौंसठ कलाएं मानी गई हैं। इनमें ललित कलाएं अन्य कलाओं से कुछ विशिष्टता रखती हैं। ललित कलाएं अपने भावनात्मक प्रदर्शन से विशुद्ध, अलौकिक, विलक्षण एवं विचक्षण के साथ ही अतुलनीय भी है। भारतीय संस्कृति की यह विशिष्टता है कि समस्त कलाओं, विधाओं के सृजन का उद्देश्य (लक्ष्य) समान है। कलाओं का अंतिम लक्ष्य व उद्देश्य मोक्ष की प्राप्ति है, जो कि मानव को समस्त दु:खों व चिंताओं से दूर करता है।

संगीत

ललित कलाओं में संगीत का स्थान सर्वोच्च है, क्योंकि इसके उपकरण ही अत्यन्त अमूर्त और चल है। जहां चित्रकला के उपकरण रेखा व रंग, काव्य के भाषा और भाव, वहां संगीत के मुख्य उपकरण मात्र स्वर और लय है। इसी खास विशिष्टता के कारण ही ललित कलाओं में संगीत अपना एक अहम्, अनूठा एवं सम्मानजनक स्थान बनाए हुए है। मानवीय भावनाओं पर संवेदनाओं को स्वरों द्वारा अभिव्यक्त करनें की अविरल धारा ही संगीत है। 
"संगीत एक अत्यन्त अद्भुत-एवं दिव्य कला है। निःसीम सम्भावनाओं से भरी जिसमें अनन्त भाव सृष्टि के निर्माण करने की अदम्य क्षमता है जिसकी व्यापक्ता व गहराई का अनुमान लगाना कल्पना से परे है।"

धार्मिक मान्यता के अनुसार ब्रह्म द्वारा सृष्टि की रचना किए जाने के फलस्वरूप ही धरती, आकाश, जल, वायु, विभिन्न जीव-जन्तुओं और मानव का जन्म हुआ। अपने आदिम रूप में मानव को न तो भाषा का ज्ञान था और न ही अपने मन की स्थिति से अवगत कराने के लिए कोई माध्यम उपलब्ध था। धीरे-धीरे मानव अपने भावों की अभिव्यक्ति ध्वन्यात्मक एवं मूक संकेतों, आंखों तथा पैरों की विभिन्न मुद्राओं के माध्यम से करने लगा। काल परिवर्तन से आवश्यकतानुसार धीरे-धीरे धवन्यात्मक एवं मूक संकेत शब्दों में और शब्द अपना समन्वित रूप धारण करके भाषा में परिवर्तित हो गए। बौद्धिक विकास के साथ-साथ मानव में संगठन एवं सहयोग की सामाजिक भावना पनपती गई और भावनाओं एवं विचारों के आदान-प्रदान के लिए सूक्ष्म से सूक्ष्म अर्थात अति सूक्ष्म माध्यमों की आवश्यकता अनुभव की जाने लगी। सम्भवतः इसी आवश्यकता ने ही मानव मन को विभिन्न प्राकृतिक उपादानों जैसे पानी के झारनें, हवा की गति, विभिन्न पशु-पक्षियों की बोलियों तथा समुद्र की लहरों की आवाज़ों की ओर आकर्षित किया। भिन्न-भिन्न ध्वनियां अपने अलग-अलग रूपों में, भिन्न भावों को जागृत करनें में सक्ष्म हैं और कहीं न कहीं कुछ ध्वनियां माधुर्य एवं लालित्य से भरी हुई हैं। इसी अनुभव ने सम्भवतः संगीत और संगीत की सार्थकता को जन्म दिया। अप्रत्यक्ष एवं प्रत्यक्ष रूप में विशिष्ट ध्वनियां, विशिष्ट भावों को मानव मन में जागृत करती है, इसमें शक की गुंजाईश नहीं। जिस प्रकार प्रत्यक्ष ध्वनियों को सार्थक शब्दों, उसके उपरांत भाषा के रूप में स्थानान्तरित किया गया वहीं प्रत्यक्ष एवं अप्रत्यक्ष ध्वनियों के संयोजन से संगीत अवतरित हो गया।

भारतीय संस्कृति का प्रथम बीज भक्ति भावना पूर्ण धरती पर जमा, शनैः शनैः अंकुरित हुआ और आज यह एक विशालकाय वृक्ष के रूप में सभी जगह फैला हुआ है। इस विशालकाय वृक्ष रूपी संगीत की आत्मा पूर्ण रूप से आध्यात्मिक है तथा सीधे मानव हृदय पर अपना प्रभाव डालती है और उसे अभिभूत कर देती है। संगीत ने भारतीय संस्कृति के उत्थान में प्रमुख भूमिका निभाई। वेदों द्वारा (में) बताए गए ईश्वर प्राप्ति के तीन साधनों यथा ज्ञान मार्ग, कर्म मार्ग एवं उपासना मार्ग में संगीत ने उपासना मार्ग को ही अपनाया।" प्राचीन ऋषि-मुनियों, चिन्तकों तथा साधकों ने संगीत को ही ईश्वर प्राप्ति का सरल-सहज मार्ग समझा तथा ईश्वर की उपासना में संगीत का ही आश्रय लिया। "भारतीय मान्यता अनुसार संगीत साक्षात् ईश्वर स्वरूप है और इसीलिए इसे 'ब्रह्मनन्द सहोदर' कहा गया है।" माधुर्य की भाषा सभी को प्रफुल्लित करने वाली ईश्वर निर्मित कला है। अनुभूतियों को चरम सीमा तक ले जाती है जो सत्चित् लौकिक विभेद से परे मोक्ष प्राप्ति का सुलभ एवं सरल साधन है। 
संगीत प्रकृति का दिया हुआ वरदान है जिसे मानव ने अपनें प्रयोगों व अनुभूतियों से प्राप्त किया। आनन्द का आविर्भाव संगीत को माना जाता है, जो साक्षात् ईश्वर का रूप है। इस साक्षात् ईश्वर रूपी संगीत में शरीर, मन और आत्मा तीनों को बलवान बनानें वाले तत्व पर्याप्त मात्रा में विद्यमान हैं। यही कारण था कि भारतीय आचार्यों एवं मनीषियों ने संगीत पर ज़ोर दिया। सामवेद में जो स्वतन्त्र सत्ता है वह उसका प्रमाण है। "नारद ने कहा "वेदानां सामवेदोस्मि" अर्थात वेदों में मैं सामवेद हूं। ऋग्वेद $(8 / 33 / 2)$ में कहा गया है-“यदि तुम संगीत के साथ ईश्वर को पुकारोगे तो वह तुम्हारी हृदय गुहा में प्रकट होकर अपना प्यार प्रदान करेगा। भगवान श्रीकृष्ण ने भी कहा है-

नाहं वसामि बैकुण्ठे योगिनां हृदय न वा।

मदभक्ताः यत्र गायन्ति तत्र तिष्ठामि नारदः।।

(नारदीय शिक्षा)

इसी प्रकार अभिनव स्वर शास्त्र में भी वर्णित है-

संगीत स्वर धारायांयेन स्वच्छीकृतं मनः।

तस्यैव जीवनं धन्यं, तेन धन्या वसुन्धरा।।"

अर्थात संगीत की मधुर स्वरधारा में जिसने अपने मन को निर्मल कर लिया है, उस का जीवन धन्य है और उस प्राणी के धन्य जीवन से वसुन्धरा धन्य है।

इसी तरह वेद, मनुर्मृति, पुराण, उपनिषद एवं अन्य ग्रन्थों में ऐसे अनेक उल्लेख मिलते हैं जिसमें संगीत के महत्त्व को बहुत अच्छे ढंग से दर्शाया गया है। सत्यम् शिवम् सुन्दरम् के भावों से भरी संगीत की पृष्ठभूमि जीवन के स्वाभाविक विकास, धार्मिक ऐश्वर्य एवं आध्यात्मिक विकास, एवं पर आधारित है।

संगीत ऐसा दिव्य नाद है जिसमें समस्त जगत (सृष्टि) के समस्त स्वर समाहित हैं। सृष्टि का बीजमन्त्र ओंमकार, ओम् या नादब्रह्म माना गया है। समस्त स्वर सृष्टि के इसी बीजमंत्र "ओंम्" से ही निष्पन्न होते हैं और इसी में विलीन हो जाते हैं। आचार्य मतंग ने नाद की व्याख्या अपने ग्रन्थ 'बृहदेशी' के देशी उत्पत्ति-प्रकरण में करते हुए बताया है कि नाद के बिना कोई संगीत या संगीत सृजन नहीं यथा-

$$
\begin{aligned}
& \text { न नादेन बिना गीतं, न नादेन बिना स्वराः। } \\
& \text { न नादेन बिना नृतं, तर्मान्नादात्मकं जगत्।। }
\end{aligned}
$$

संगीत कला भिन्न-भिन्न नादों का संयोग मात्र है। अतः संगीत से उत्पन्न हुआ नाद ही ईश्वर का साक्षात् रूप है। विभिन्न ग्रन्थों में वर्णित है कि यह समस्त जगत (सृष्टि) नाद के अधीन है-"नादाधीनं जगत सर्वम्।" संगीत विश्व में व्याप्त विशाल चेतना का ध्वन्यात्मक स्पन्दन है। 


\section{मानवीय आभामंडल}

समस्त जगत में जंगम व स्थावर पदार्थों के भिन्न-भिन्न प्रकार के अच्छे-बुरे गुणधर्म होते हैं, जो नज़रों मे सहज ही आ जाते हैं। सीधे तौर पर इसे इस तरह समझा जा सकता है- जब पत्थर को पत्थर से टकराया जाता है, तो उससे चिंगारियां पैदा होती हैं। देखने में तो दोनों ही पत्थर हैं परन्तु उनके अन्दर अग्नि है। इस प्रकार चिंगारियां और आग पैदा करना पत्थर का विशेष गुणधर्म है। जगत में जंगल का राजा शेर अन्य जानवरों को मारकर खाता है, वह निडर व पराकमी है, शेर का गुणधर्म निडरता और पराक्रम है। ठीक ऐसे ही गुणधर्म मानव में भी हैं, ये गुणधर्म अच्छे-बुरे दोनों होते हैं। यदि किसी मनुष्य में कोई विशेष गुणधर्म न हो तो उसमें मनुष्यत्त्व नहीं होगा। इसी विशेष अच्छे-बुरे गुणधर्म को ही 'आभा' कहते हैं। समाज में किसी भी मनुष्य में किसी विशेष गुणधर्म का अधिक प्राकट्य होने पर वह समाज में प्रमुख रूप से नज़र आता है और वह समाज के अन्य लोगों से भला और बुरा हो जाता है। ऐसे लोग जिनमें अच्छा गुणधर्म होता है, उन्हें देखते ही मुख से सहज ही निकल जाता है, वाह! क्या तेजस्वी पुरूष है। ये तेज़ ही उस व्यक्ति का 'आभामंडल' कहलाता है।

आभामंडल को रंगों के आधार पर छ: भागों मे विभक्त किया गया है।

1 काला

2 नीला

3 हरा

4 लाल

5 हल्का नीला

6 शंख के समान श्वेत।

ये सभी रंग भौतिक परमाणुओं के सम्मिश्रण के कारण होते हैं। वैज्ञानिक भाषा में आभामंडल को ऊर्जा क्षेत्र या जैव क्षेत्र कहते हैं।

मानवीय आभामंडल को नंगी आंख द्वारा नहीं देखा जा सकता है। इसके लिए वैज्ञानिकों ने अपनी मेहनत द्वारा ऐसे उपकरण बना लिए हैं जिनके द्वारा आभामंडल को देखना आम आदमी के लिए सरल व सुगम हो पाया है। कुछ यन्त्रों के नाम निम्नलिखित हैं-

1 किर्लियन फोटाग्राफी

2 GDV (गैस डिस्चार्च विजुअलाईजेशन)

3 RFI (Resonant Field Imaging) 


\section{निष्कर्ष}

संगीत मानव ही क्या समस्त जगत के प्रणियों को अपनी ओर आकर्षित करता है। संगीत से यदि मानव आकर्षित होता है तो उसके आभामंडल पर इसका प्रभाव पड़ेगा ही यह तया है। अर्थात कहने का अर्थ यह है कि सांगीतिक प्रभाव जिसे आज हम संगीत चिकित्सा के नाम से भी जानते हैं इसके द्वारा आभामंडल पर सकारात्मक प्रभाव डालकर बीमार लोगों को ठीक भी किया जाता है। संगीत चिकित्सा में भी मानवीय आभामंडल को वैज्ञानिक उपकरणों द्वारा देखा जाता है तथा आभामंडल की विकृत स्थिति को देख कर उसे संगीत द्वारा ठीक किया जाता है।

सन्दर्भ ग्रन्थ सूची

फात्मा, डॉ. निशात (1995), गोसी लोकगीत, समाज, सस्कृति और साहित्य, कनिष्का पब्लिशर्स, डिस्ट्रीब्यूटर्स नई दिल्ली

शर्मा पं. श्रीराम आचार्य (1995) प्राणशक्ति एक दिव्य विभूति, वाङ्मय-17 अखंड ज्योति संस्थान मथुरा

कुमार डॉ प्रवीण (2007),योग परिचय एवं परम्परा, खेल साहित्य केन्द्र, नई दिल्ली 